...this contract change is the biggest since

the NHS was founded 57 years ago.

\title{
The President's New Year message
}

In 1996 I asked the question 'So who wants change?' in a guest leader in the $B D J$. I wrote about the then increased consumerism and regulatory controls, and how access to NHS dental services was becoming restricted as a consequence of these. I described how the acceptance of the 1993 Nuffield Report on the education and training of dental auxiliaries (PCDs) would be an imminent watershed for UK dentistry. I also suggested that there was an increasing culture of setting up trials by those in power, then decisions made before the result of the trials were known. I ended by asking for dentistry to proceed [with change] in an orderly and planned manner, with proper assessment and consultation at every stage.

As we embark on a new year - arguably with dentistry facing the biggest changes - indeed the biggest challenges since we formed a separate, independent profession in 1878, each individual will decide whether what has subsequently happened has fulfilled my plea of 1996.

During the next few months we will have an expansion of our workforce which is unprecedented since the first dental register was introduced. The Department of Health is committed to ensuring that the numbers of whole time equivalents dentists in England increases by 7\%. This will have to be achieved by persuading many who are not working full-time, indeed even at all, to increase their commitment to clinical practice. It will also mean that large numbers of overseas dentists will need to be cajoled into leaving their own cultures to come and work here. There is going to be a need for a great deal of support by the BDA, indeed all of us, for all these colleagues who find themselves offering clinical care in an alien environment.

This all happens at the same time as the first real steps in the regulation of private dentistry - albeit only with the introduction of a non-NHS complaints system, which everyone will have to sign up to. And, the relaxation of the rules about corporate practice may well have a substantial effect on the shape and form of general practice.

We are also embarking on a new era for our fellow professionals - the Professionals Complementary to
Dentistry. The introduction this year of a single registration list for all of them (including dental nurses and technicians) based on their training and competency will have a profound effect on how we work with them in the future, in my opinion. I suggest that we are starting a revolution in the delivery of oral healthcare. Some will decry this as a dilution of dentists' professional status, but I believe that given a proper strategy and planning, the changes should be to the benefit of all stakeholders.

The final major change I refer to is the introduction of a new contract for NHS GDPs. For many who rely on the NHS for the bulk of their income, this represents for them the biggest change to their livelihood in the foreseeable future. Whilst this contract change is the biggest since the NHS was founded 57 years ago, this New Year message is not the place to enter into debate about the advantages (if any!) or the disadvantages of what will be on offer. However, we must not lose sight of the fact that NHS contract changes do take place fairly regularly and I guess will continue to do so in the not too distant future. And for many the change in 2005 will offer opportunities to improve their (and their dental team's) working lives in or outside the NHS system. For them, October 2005 will be a watershed in their careers.

I am confident for the future of dentistry in the UK, and that the BDA will be able to assist its members in fulfilling whatever their objectives are for the New Year. In August 2003, respected commentator John Humphries wrote in the Sunday Times 'It is possible to imagine a world without many of the luxuries we take for granted today - but a world without dentists? Unthinkable'. Whilst conceding that dentists were not entirely blameless [for the ills of NHS dentistry] he suggested that we were 'more sinned against than sinning'. In my opinion he merely reflects my view that overwhelmingly, we have the support of our customers, the UK public.

I wish all dentists, their teams and their patients a Happy New Year.

Anthony S. Kravitz OBE, President BDA doi:10.1038/sj.bdj.4811945 